\title{
昌宁-孟连结合带南汀河早古生代辉长岩锆石年代学及 地质意义
}

\author{
王保弟”, 王立全, 潘桂棠, 尹福光, 王冬兵, 唐渊 \\ 成都地质矿产研究所, 成都 610081 \\ *联系人, E-mail: baodiwang@163.com \\ 2012-06-28 收稿, 2012-08-28 接受 \\ 国家重点基础研究发展计划(2009CB421003)、国家自然科学基金(41073033, 40872055)和中国地质调查局项目(1212011121259, 1212011085119) \\ 资助
}

\begin{abstract}
摘要 昌宁-孟连结合带南汀河地区发育比较完整的蛇绿岩组合, 由变质橄览岩、堆晶辉长岩、 变质辉长岩、斜长角闪岩以及玄武岩等构造单元组成. 通过该蛇绿岩中堆晶辉长岩以及辉长岩 的 LA-ICPMS 锆石 U-Pb 定年研究显示, 堆晶辉长岩有两种类型的岩浆锆石, ${ }^{206} \mathrm{~Pb} /{ }^{238} \mathrm{U}$ 加权平 均年龄分别为 $473.0 \pm 3.8 \mathrm{Ma}$ 和 $443.6 \pm 4.0 \mathrm{Ma}$, 分别代表了堆晶辉长岩早期与晚期岩浆作用事件 的时代; 而辉长岩 16 个测点加权平均年龄为 $439.0 \pm 2.4 \mathrm{Ma}$. 地球化学分析表明, $\mathrm{SiO}_{2}$ 含量在 46.46\% $52.11 \%$ 之间, $\mathrm{TiO}_{2}$ 含量为 $0.96 \% \sim 1.14 \%, \mathrm{~K}_{2} \mathrm{O}$ 含量为 $0.48 \% ~ 0.75 \%$; $\mathrm{REE}$ 配分曲线呈弱 亏损型及富集型，微量元素蛛网图与洋中脊玄武岩类似，部分样品高场强元素 $\mathrm{Nb}, \mathrm{Ta}, \mathrm{Zr}, \mathrm{Hf}, \mathrm{Ti}$ 亏损, 指示这些岩石可能形成于弧后裂谷盆地环境. 堆晶辉长岩晚期岩浆结晶时代与辉长岩结 晶时代基本一致, 表明南汀河地区存在 444 439 $\mathrm{Ma}$ 的弧后盆地, 这是昌宁-孟连结合带首次精 确限定的早古生代蛇绿岩. 南汀河蛇绿岩与危塘地区龙木错-双湖结合带中段果干加年山以及桃 形湖盆地形成时代一致, 地球化学性质相似, 本文认为昌宁-孟连结合带与龙木错-双湖结合带可 能一起代表了一个统一的古特提斯洋壳的残余.
\end{abstract}

关键词

昌宁-孟连

结合带

龙木错-双湖

结合带

南汀河

早古生代

堆晶辉长岩
昌宁-孟连结合带位于特提斯构造域，其洋盆的 形成时代对于恢复特提斯洋的形成演化和古地理格 局的重建等具有重要意义. 虽然越来越多的地球科 学家认为, “三江地区”特提斯演化阶段存在多个陆壳 地块群与洋盆相间排列的多岛洋格局的观点, 并认 为昌宁-孟连结合带代表了特提斯的主洋盆位置 ${ }^{[1 ~ 6]}$. 但对昌宁-孟连结合带所代表洋盆的打开时限还存在 着激烈的争议, 不少学者根据下石炭统平掌组洋岛 型和洋壳型玄武岩认为昌宁-孟连洋盆形成于早石炭 世 ${ }^{[7]}$; 也有学者根据铜厂街火山岩同位素资料认为昌 宁-孟连特提斯洋壳形成于泥盆纪 ${ }^{[3,8]}$; 杨文强等人 ${ }^{[9]}$ 根据滇西南耿马一带昌宁-孟连结合带枕状玄武岩伴 生有晚泥盆世放射虫和牙形石的硅质岩、硅质泥岩,
也认为昌宁-孟连特提斯洋盆在晚泥盆世已经形成 ${ }^{[9]}$ 由于昌宁-孟连结合带缺乏高精度的同位素年龄资料, 从而限制了特提斯洋演化的深人研究, 本文通过对 昌宁-孟连结合带南汀河一带蛇绿岩中具有残余层状 结构堆晶辉长岩以及辉长岩进行 LA-ICPMS 锆石 $\mathrm{U}-\mathrm{Pb}$ 定年, 探讨其地质意义, 为特提斯洋的构造演 化提供重要信息.

\section{1 地质背景与岩石学特征}

昌宁-孟连结合带北起昌宁、云县铜厂街, 向南 沿双江、澜沧老厂至孟连一线展布，向南延人缅甸. 该带内发育较完整的蛇绿混杂岩, 西侧为保山地块 古生代稳定台型浅海陆棚碳酸盐沉积和滨海-浅海相 
砂泥质沉积; 其东侧为临沧-㖵海岩浆弧带(图 1(a)). 南汀河蛇绿混杂岩带出露于永德县班控-南汀河-铜 厂街一带, 研究区断续出露总长度约 $80 \mathrm{~km}$, 出露宽 度 $0.5 \sim 3 \mathrm{~km}$ 不等. 该蛇绿混杂岩南部构造侵位于晚
古生代地层之中，其中泥盆系为含碳质-硅质碎屑岩 组合的温泉(岩)组 $(\mathrm{D} w)$ 、泥盆系-石炭系为浅变质砂板 岩组合的南段组( DCn), 是晚古生代昌宁-孟连扩张 洋盆中堆积的半深海-深海硅泥质复理石及火山岩建

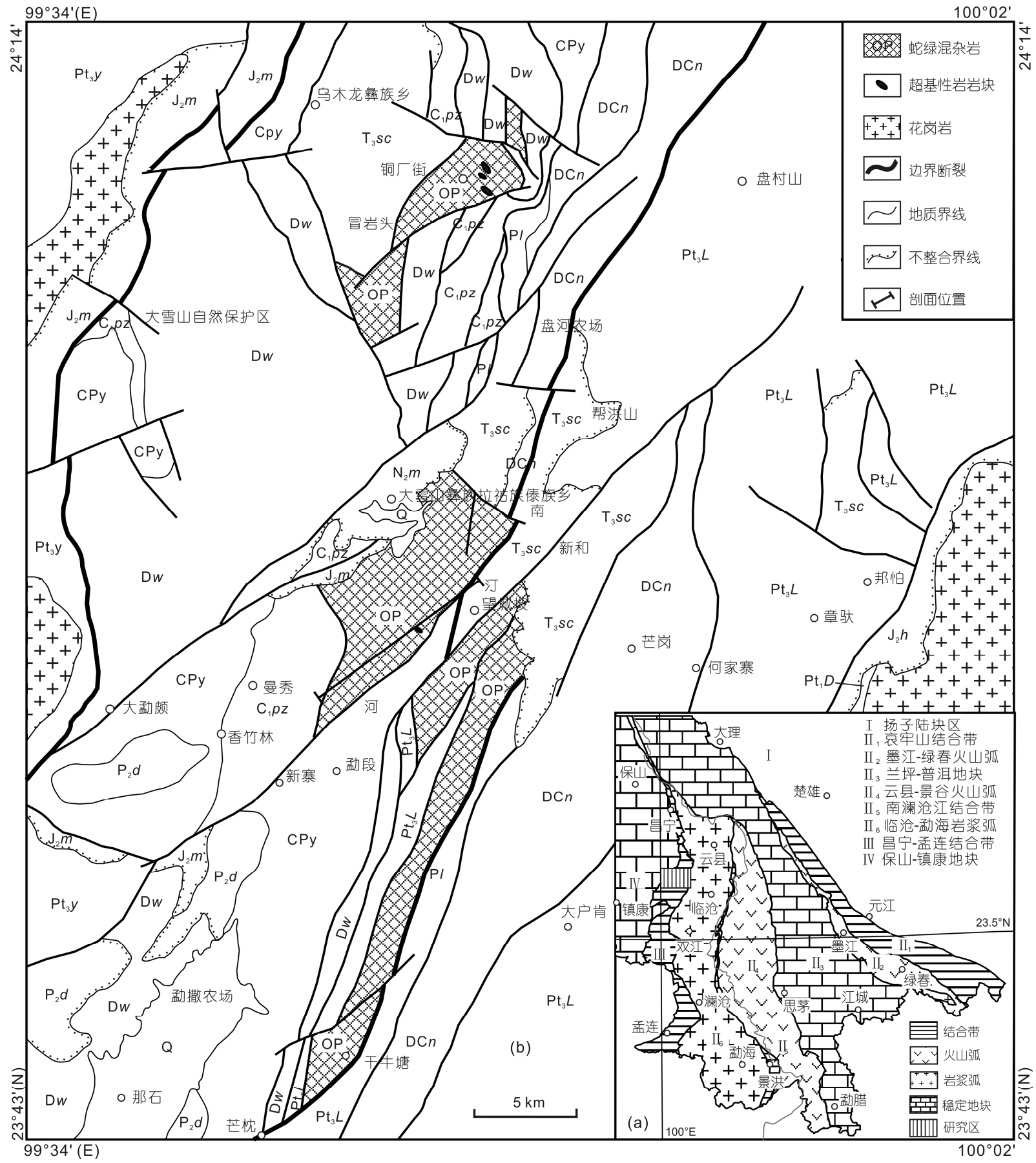

图 1 西南三江构造带地质简图(a)和南汀河地区地质简图(b)

$\mathrm{Q}$, 第四系未分; $\mathrm{N}_{2} m$, 芒棒组; $\mathrm{N}_{1} s h$, 三号沟组 $\mathrm{J}_{2} m$, 预戛组; $\mathrm{T}_{3} s c$, 三岔河组; $\mathrm{Pl}$, 拉巴组; $\mathrm{P}_{2} d$, 大明山组; $\mathrm{CP} y$, 渔塘寨组 $; \mathrm{C}_{1} p z$, 平掌组; $\mathrm{D} w$, 温 泉组; $\mathrm{DC} n$, 南段组; $\mathrm{Pt}_{3} y$, 允沟岩组; $\mathrm{Pt}_{3} L$, 澜沧岩群变质岩系; $\mathrm{Pt}_{1} D$, 大预龙岩组 
造; 下石炭统为中基性火山岩-火山角砾岩-灰岩-碎 屑岩组合的平掌组 $\left(\mathrm{C}_{1} p z\right)$ 、石炭系-二叠系为鲕粒-生 物碎屑灰岩的渔塘寨组 $(\mathrm{CP} y)$ 、中二叠统为鲚粒-生物 碎屑灰岩的大明山组 $\left(\mathrm{P}_{2} d\right)$, 是洋盆扩张过程中的洋 岛或洋内弧火山-沉积建造(图 1(b) $)^{[10]}$. 蛇绿岩残块 岩石类型以斜长角闪岩、绿泥绿帘阳起石片岩、钠长 绿泥绿帘片岩、蛇纹石化橄榄辉石岩、蛇纹石化辉橄 岩、堆晶辉长岩、变辉长岩以及变玄武岩等为主, 超 基性岩块多呈层状-似层状、囊状、团块状产出. 恢复 的蛇绿岩“基本层序”不完整：主要为变质橄榄岩、堆 晶杂岩、变辉长岩以及基性熔岩单元组成(图2), 各单 元之间皆为断层接触.

本文分析样品为均质辉长岩和堆晶辉长岩, 二 者未见直接接触关系, 辉长岩采样位置 GPS 坐标 为: $23^{\circ} 59^{\prime} 04.0^{\prime \prime} \mathrm{N}, 99^{\circ} 42^{\prime} 38.6^{\prime \prime} \mathrm{E}$; 堆晶辉长岩出露宽 度约 $1 \mathrm{~km}$, 采样位置 GPS 坐标为: $23^{\circ} 59^{\prime} 22.3^{\prime \prime} \mathrm{N}$, $99^{\circ} 43^{\prime} 26.3^{\prime \prime} \mathrm{E}$ (图 2). 辉长岩显微镜下显定向构造、中 细粒辉长结构, 虽有次闪石化, 仍有辉石残留, 斜长 石帘石化、葡萄石化. 堆晶辉长岩具有由暗色和浅色 纹层韵律组成的层纹状构造, 韵律层序非常清楚(图 3(a)), 总体反映出典型的岩浆结晶分异堆积结构特 征, 堆晶岩暗色部位多为辉石和角闪石 (阳起石), 浅 色部位多为斜长石, 并发生了䵢帘石化, 局部还可见
石英; 具有细-中粒状结构, 粒度一般为 $0.5 \sim 2.0 \mathrm{~mm}$, 矿物组成为斜长石 $(30 \%$ ～45\%)、透闪石-阳起石 $(15 \%$ $20 \%)$ 、绿帘石 $(15 \%$ 20\%)、石英 $(3 \%$ ％）、碳酸盐 (3\% 5\%)(图 3(b)); 其中斜长石为更长石, 透闪石-阳 起石呈长柱状不均匀分布于绿帘石集合体中，局部 可见辉石残余或假象，绿帘石为它形粒状、不规则状 集合体，石英呈细粒状填隙物且分布极不均匀.

\section{2 分析方法}

锆石单矿物分选在河北省区域地质调查研究所 实验室完成，在严格避免污染的条件下，采用常规重 力及电磁分选, 然后在双目显微镜下手工挑纯. 锆石 制靶后 CL 图像在西北大学大陆动力学国家重点实验 室 FEI Quanta 400 FEG 扫描电子显微镜上完成.

锆石微区 U-Pb 同位素定年和锆石微量元素含量 在中国地质大学(武汉)地质过程与矿产资源国家重点 实验室(GPMR)利用 LA-ICPMS 同时分析完成. 激光 剥蚀系统为 GeoLas 2005, ICP-MS 为 Agilent 7500a 对分析数据的离线处理(包括对样品和空白信号的选 择、仪器灵敏度漂移校正、元素含量及 U-Th-Pb 同位 素比值和年龄计算)采用软件 ICPMSDataCal ${ }^{[11,12]}$ 完成. 详细的仪器操作条件和数据处理方法同文献[11,12]. 锆石样品的 U-Pb 年龄谐和图绘制和年龄权重平均计

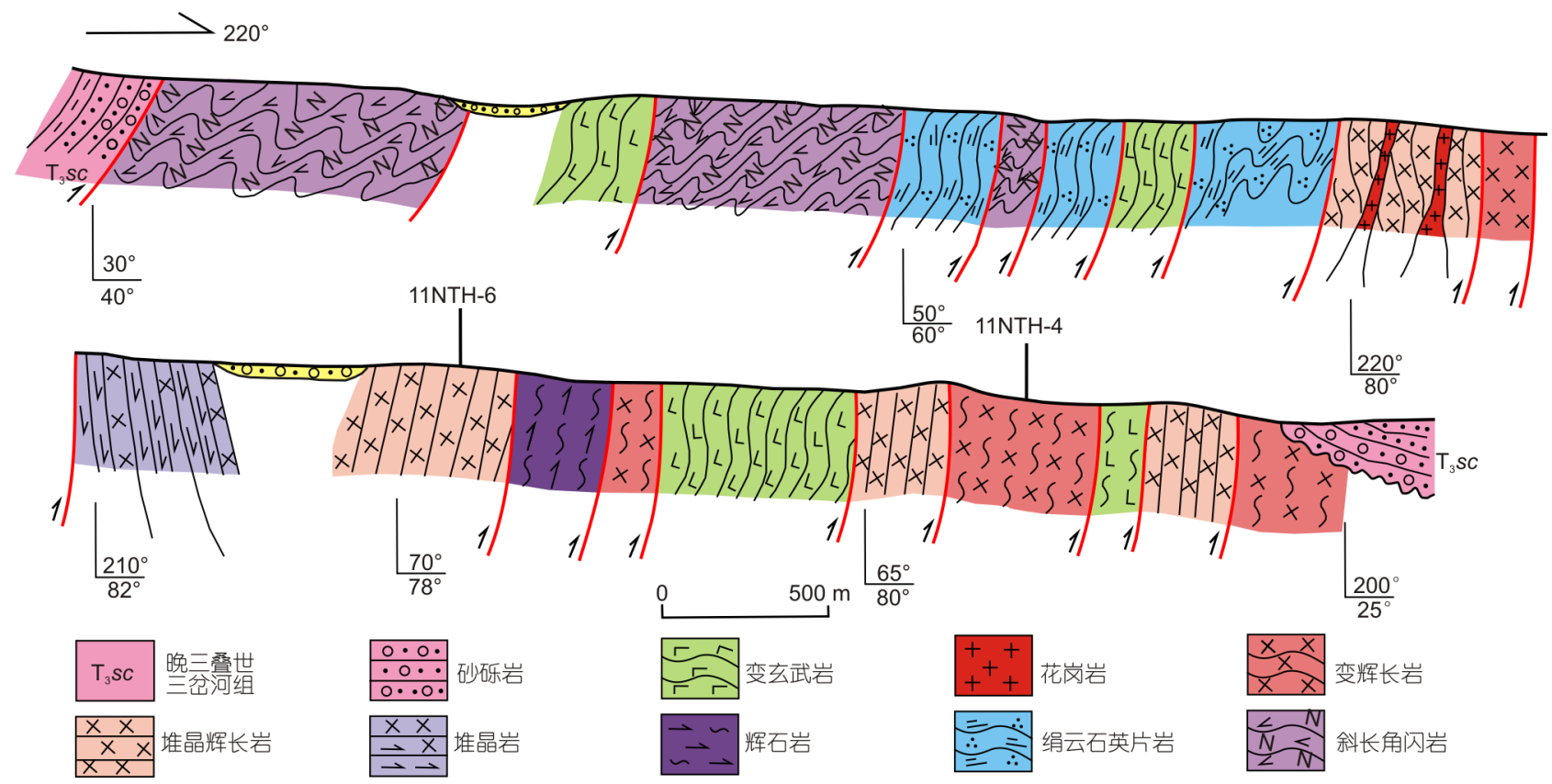

图 2 昌宁-孟连结合带南汀河蛇绿岩剖面 

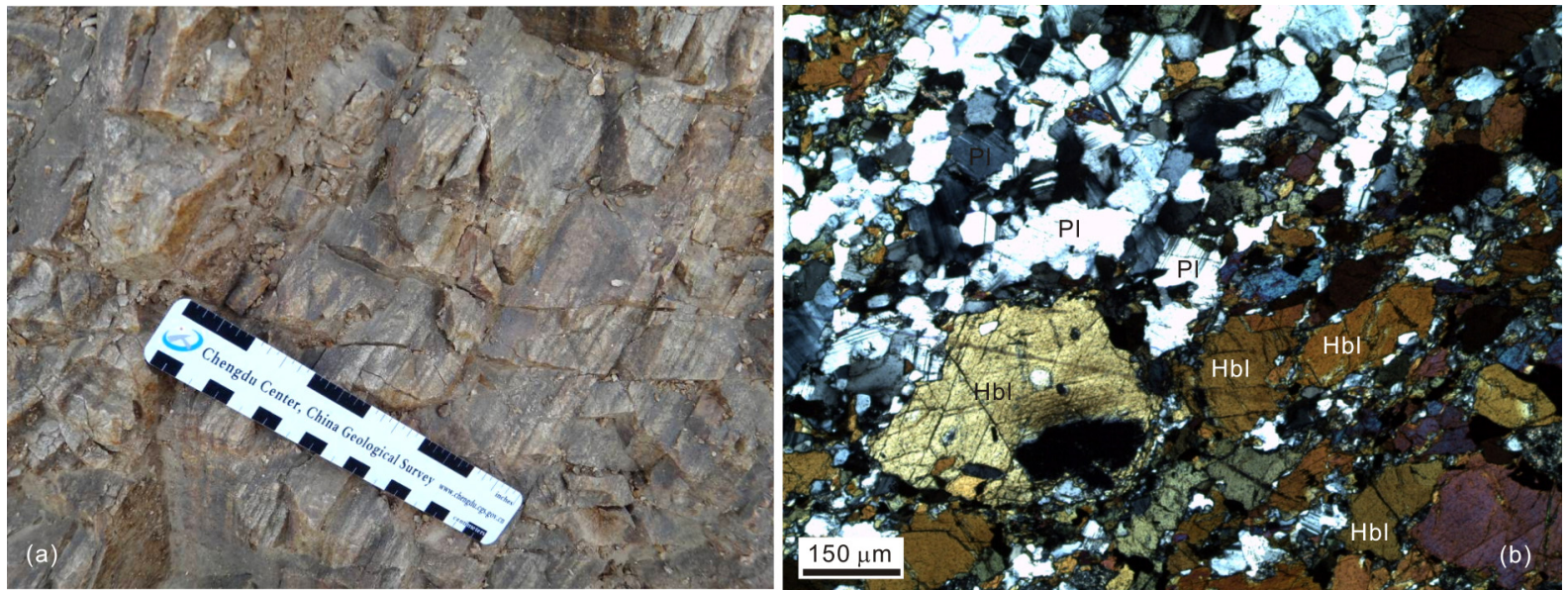

图 3 南汀河蛇绿岩堆晶辉长岩野外产出特征(a)及显微镜下特征(b)

$\mathrm{Pl}$, 斜长石; $\mathrm{Hbl}$, 角闪石

算均采用 Isoplot/Ex_ver3 $3^{[13]}$ 完成. 其分析结果见表 1.

主量元素分析在成都地质矿产研究所采用 XRF (Rigaku RIX 2100 型)玻璃熔饼法完成, 分析精度优 于 $4 \%$. 微量元素采用酸溶法, 在同位素地球化学国 家重点实验室用 PE Elan6000 型 ICP-MS 仪器测定 分析, 分析精度一般好于 $2 \%$ 5\%; 微量元素分析流 程见 Chen 等人 ${ }^{[14]}$ 的描述. 主、微量元素分析结果见 表 2 .

\section{3 分析结果}

\section{1 锆石 U-Pb 年代学}

辉长岩样品(11NTH-4)的锆石粒度普遍较小(60 $100 \mu \mathrm{m})$, 多数颗粒内部具有与晶体边界基本一致、宽 的岩浆结晶振荡 CL 环带(图 4(a)), 而有少许锆石颗 粒没有明显的岩浆结晶震荡 CL 环带, 显示均一的图 像特征; 另外有一些锆石具有较宽结晶环带的边缘 发育锆石增长边(图 4(a)). 一般认为, 岩浆成因锆石 的 $T h / U$ 比值大于 0.3 , 且 $T h$ 和 $U$ 之间具有明显的正 相关, 而变质重结晶锆石则小于 $0.1^{[15,16]}$. 样品 $11 \mathrm{NTH}-4$ 共测定 20 颗锆石, 除 7,8,13 和 14 号测点 ${ }^{206} \mathrm{~Pb} /{ }^{238} \mathrm{U}$ 年龄为 $338 \sim 318 \mathrm{Ma}$, 与总体年龄明显不和 谐外(可能因粒度太小而发生了显著的 $\mathrm{Pb}$ 丢失), 其 余 16 个分析点均为自形程度高、显示结晶环带的锆 石, 它们具有一致的 ${ }^{206} \mathrm{~Pb} /{ }^{238} \mathrm{U}$ 年龄. 在这 16 个分 析点中, 有 6 颗锆石 (测点 01, 05, 09, 11, 15 和 23) 显 示具有较宽的结晶 CL 环带, 在其外围有和内部结
构不协调的锆石增长边, 由于该增长边太窄而无法 进行分析, 但其外围 CL 特征类似于变质的锆石. 这 16 颗锆石的 $U$ 和 $T h$ 含量分别为 52.9 177 ppm, 38.0 $92.2 \mathrm{ppm}, \mathrm{Th} / \mathrm{U}$ 均较高, 为 $0.39 \sim 0.72$ (表 1 ), 且 $\mathrm{Th}$ 与 $\mathrm{U}$ 存在正相关关系(图未附), 显示本文测定的锆 石为岩浆成因 ${ }^{[16]}$. 其锆石 16 个分析点的 ${ }^{206} \mathrm{~Pb} /{ }^{238} \mathrm{U}$ 年龄为 429 452 $\mathrm{Ma}$ (表 1), 在一致曲线图中, 数据点 成群分布(图 5(a)), 其 ${ }^{206} \mathrm{~Pb} /{ }^{238} \mathrm{U}$ 年龄的加权平均值 为 $439.0 \pm 2.4 \mathrm{Ma}(\mathrm{MSWD}=0.64, n=16)$. 根据该辉长岩 的岩相学以及锆石的形态、 Th/U 比值和 CL 图像特 征, 本文将 $439 \mathrm{Ma}$ 解释为辉长岩的结晶年龄.

堆晶辉长岩样品(11NTH-6)的锆石粒度明显比辉 长岩的粒度要大 $(100 \sim 200 \mu \mathrm{m})$, 大多数锆石为柱状自 形晶(长/宽 $\approx 2 \sim 3$ ), 锆石 CL 图像具有两种不同的形 态, 一种是具有明显岩浆结晶振荡 CL 环带的老核, 边部发育锆石增长边, 增长边大多太窄而无法进行 分析, 其 CL 特征总体类似于变质的锆石; 另外一种 是锆石颗粒内部具有与晶体边界基本一致、宽窄不一 的岩浆结晶振荡 CL 环带(图 4(b)). 对这两种类型的 锆石分别进行了 11 和 9 个点的测定(图 5(b)). 第一种 11 个分析点均为具有锆石增长边的锆石, $\mathrm{U}$ 和 $\mathrm{Th}$ 含量分别为 84.2 196 ppm, 44.2 180 ppm, Th/U 均较 高, 为 $0.52 \sim 1.05$ (表 1), 显示测定的锆石为岩浆成 因 ${ }^{[16]}$, 其锆石 11 个分析点的 ${ }^{206} \mathrm{~Pb} /{ }^{238} \mathrm{U}$ 年龄为 $471 \sim$ $478 \mathrm{Ma}$ (表 1), 在一致曲线图中, 数据点成群分布(图 $5(\mathrm{c})),{ }^{206} \mathrm{~Pb} /{ }^{238} \mathrm{U}$ 加权平均年龄为 $473.0 \pm 3.8 \mathrm{Ma}$ (MSWD=0.7, n=11). 第二种 9 个分析点均为自形程 
表 1 昌宁-孟连结合带南汀河蛇绿岩堆晶辉长岩及辉长岩锆石 U-Pb 年龄分析数据 ${ }^{\text {a) }}$

\begin{tabular}{|c|c|c|c|c|c|c|c|c|c|c|c|c|c|c|c|c|}
\hline \multirow[b]{2}{*}{ 测点 } & \multirow[b]{2}{*}{$\begin{array}{c}\mathrm{Pb} \\
(\mathrm{ppm})\end{array}$} & \multirow[b]{2}{*}{$\begin{array}{c}\text { Th } \\
(\mathrm{ppm})\end{array}$} & \multirow[b]{2}{*}{$\begin{array}{c}\mathrm{U} \\
(\mathrm{ppm})\end{array}$} & \multirow[b]{2}{*}{$\mathrm{Th} / \mathrm{U}$} & \multicolumn{2}{|c|}{${ }^{207} \mathrm{~Pb} /{ }^{206} \mathrm{~Pb}$} & \multicolumn{2}{|c|}{${ }^{207} \mathrm{~Pb} /{ }^{235} \mathrm{U}$} & \multicolumn{2}{|c|}{${ }^{206} \mathrm{~Pb} /{ }^{238} \mathrm{U}$} & \multicolumn{2}{|c|}{${ }^{207} \mathrm{~Pb} /{ }^{206} \mathrm{~Pb}$} & \multicolumn{2}{|c|}{${ }^{207} \mathrm{~Pb} /{ }^{235} \mathrm{U}$} & \multicolumn{2}{|c|}{${ }^{206} \mathrm{~Pb} /{ }^{238} \mathrm{U}$} \\
\hline & & & & & 比值 & $1 \sigma$ & 比值 & $1 \sigma$ & 比值 & $1 \sigma$ & $\begin{array}{l}\text { 年龄 } \\
(\mathrm{Ma})\end{array}$ & $1 \sigma$ & $\begin{array}{l}\text { 年龄 } \\
(\mathrm{Ma})\end{array}$ & $1 \sigma$ & $\begin{array}{l}\text { 年龄 } \\
(\mathrm{Ma})\end{array}$ & $1 \sigma$ \\
\hline \multicolumn{17}{|c|}{11 NTH-4 } \\
\hline 1 & 13.8 & 86.8 & 146 & 0.59 & 0.057 & 0.003 & 0.544 & 0.029 & 0.071 & 0.0012 & 476 & 126 & 441 & 19 & 444 & 7 \\
\hline 2 & 5.46 & 28.8 & 61.9 & 0.46 & 0.079 & 0.006 & 0.711 & 0.046 & 0.069 & 0.0016 & 1162 & 150 & 545 & 27 & 431 & 9 \\
\hline 3 & 10.7 & 63.4 & 120 & 0.53 & 0.065 & 0.004 & 0.616 & 0.035 & 0.070 & 0.0014 & 787 & 126 & 488 & 22 & 434 & 9 \\
\hline 4 & 9.08 & 46.3 & 101 & 0.46 & 0.069 & 0.005 & 0.663 & 0.043 & 0.072 & 0.0014 & 898 & 138 & 516 & 26 & 446 & 8 \\
\hline 5 & 6.42 & 33.7 & 74.7 & 0.45 & 0.066 & 0.005 & 0.631 & 0.045 & 0.070 & 0.0016 & 809 & 147 & 497 & 28 & 437 & 9 \\
\hline 6 & 7.61 & 36.0 & 89.5 & 0.40 & 0.066 & 0.006 & 0.628 & 0.050 & 0.070 & 0.0012 & 794 & 176 & 495 & 31 & 436 & 7 \\
\hline 7 & 2.72 & 0.17 & 46.3 & 0.01 & 0.113 & 0.009 & 0.752 & 0.047 & 0.054 & 0.0017 & 1844 & 151 & 569 & 27 & 338 & 10 \\
\hline 8 & 4.10 & 0.42 & 73.3 & 0.01 & 0.093 & 0.007 & 0.620 & 0.043 & 0.051 & 0.0013 & 1480 & 105 & 490 & 27 & 318 & 8 \\
\hline 9 & 15.5 & 92.2 & 177 & 0.52 & 0.058 & 0.003 & 0.545 & 0.029 & 0.069 & 0.0011 & 517 & 117 & 442 & 19 & 432 & 7 \\
\hline 10 & 12.4 & 68.3 & 141 & 0.49 & 0.059 & 0.004 & 0.565 & 0.032 & 0.071 & 0.0012 & 572 & 135 & 455 & 21 & 440 & 7 \\
\hline 11 & 12.3 & 85.4 & 138 & 0.62 & 0.061 & 0.004 & 0.572 & 0.035 & 0.070 & 0.0014 & 639 & 138 & 459 & 23 & 436 & 8 \\
\hline 12 & 7.64 & 37.4 & 89.2 & 0.42 & 0.058 & 0.004 & 0.550 & 0.036 & 0.071 & 0.0015 & 524 & 186 & 445 & 24 & 442 & 9 \\
\hline 13 & 5.57 & 0.85 & 97.1 & 0.01 & 0.080 & 0.006 & 0.530 & 0.036 & 0.051 & 0.0012 & 1198 & 152 & 432 & 24 & 320 & 7 \\
\hline 14 & 16.0 & 4.18 & 275 & 0.02 & 0.056 & 0.003 & 0.412 & 0.024 & 0.054 & 0.0009 & 454 & 131 & 351 & 17 & 339 & 6 \\
\hline 15 & 9.14 & 44.9 & 106 & 0.42 & 0.066 & 0.004 & 0.646 & 0.039 & 0.072 & 0.0015 & 1200 & 135 & 506 & 24 & 446 & 9 \\
\hline 16 & 10.0 & 68.4 & 112 & 0.61 & 0.057 & 0.004 & 0.540 & 0.035 & 0.070 & 0.0013 & 494 & 146 & 438 & 23 & 434 & 8 \\
\hline 17 & 4.96 & 38.0 & 52.9 & 0.72 & 0.084 & 0.007 & 0.812 & 0.065 & 0.073 & 0.0018 & 1300 & 159 & 604 & 36 & 451 & 11 \\
\hline 18 & 9.34 & 51.2 & 103 & 0.50 & 0.064 & 0.004 & 0.629 & 0.036 & 0.073 & 0.0014 & 752 & 130 & 496 & 22 & 452 & 8 \\
\hline 19 & 5.61 & 34.4 & 65.1 & 0.53 & 0.067 & 0.005 & 0.628 & 0.039 & 0.069 & 0.0016 & 850 & 148 & 495 & 24 & 429 & 10 \\
\hline 20 & 4.65 & 21.6 & 55.1 & 0.39 & 0.076 & 0.005 & 0.703 & 0.042 & 0.070 & 0.0016 & 1083 & 127 & 541 & 25 & 437 & 10 \\
\hline \multicolumn{17}{|c|}{11 NTH-6 } \\
\hline 1 & 6.80 & 59.7 & 73.7 & 0.81 & 0.083 & 0.006 & 0.793 & 0.050 & 0.071 & 0.0016 & 1276 & 130 & 593 & 28 & 440 & 10 \\
\hline 2 & 3.08 & 12.1 & 35.0 & 0.35 & 0.127 & 0.010 & 1.145 & 0.076 & 0.072 & 0.0024 & 2050 & 141 & 775 & 36 & 449 & 14 \\
\hline 3 & 7.99 & 44.2 & 84.3 & 0.52 & 0.079 & 0.005 & 0.825 & 0.058 & 0.077 & 0.0017 & 1161 & 136 & 611 & 33 & 478 & 10 \\
\hline 4 & 11.1 & 69.0 & 114 & 0.61 & 0.080 & 0.005 & 0.830 & 0.050 & 0.077 & 0.0014 & 1194 & 129 & 613 & 28 & 477 & 8 \\
\hline 5 & 15.1 & 104 & 156 & 0.67 & 0.058 & 0.003 & 0.609 & 0.033 & 0.077 & 0.0013 & 520 & 126 & 483 & 21 & 475 & 8 \\
\hline 6 & 14.0 & 116 & 150 & 0.77 & 0.058 & 0.004 & 0.569 & 0.039 & 0.071 & 0.0014 & 539 & 149 & 457 & 25 & 444 & 8 \\
\hline 7 & 4.17 & 26.3 & 48.4 & 0.54 & 0.118 & 0.012 & 1.031 & 0.064 & 0.071 & 0.0023 & 1920 & 189 & 719 & 32 & 444 & 14 \\
\hline 8 & 9.39 & 81.0 & 102 & 0.80 & 0.066 & 0.004 & 0.602 & 0.040 & 0.071 & 0.0022 & 794 & 139 & 478 & 25 & 441 & 13 \\
\hline 9 & 19.4 & 155 & 196 & 0.79 & 0.064 & 0.004 & 0.655 & 0.036 & 0.076 & 0.0012 & 744 & 124 & 511 & 22 & 471 & 7 \\
\hline 10 & 18.9 & 180 & 184 & 0.98 & 0.062 & 0.003 & 0.646 & 0.033 & 0.076 & 0.0012 & 680 & 113 & 506 & 20 & 473 & 7 \\
\hline 11 & 19.5 & 187 & 192 & 0.98 & 0.067 & 0.003 & 0.676 & 0.032 & 0.073 & 0.0010 & 848 & 102 & 525 & 19 & 455 & 6 \\
\hline 12 & 23.5 & 262 & 237 & 1.11 & 0.055 & 0.003 & 0.530 & 0.027 & 0.070 & 0.0010 & 433 & 126 & 432 & 18 & 438 & 6 \\
\hline 13 & 19.8 & 206 & 197 & 1.04 & 0.060 & 0.003 & 0.576 & 0.032 & 0.071 & 0.0011 & 587 & 122 & 462 & 21 & 441 & 6 \\
\hline 14 & 10.3 & 65.2 & 105 & 0.62 & 0.059 & 0.004 & 0.605 & 0.041 & 0.076 & 0.0014 & 583 & 146 & 480 & 26 & 473 & 9 \\
\hline 15 & 17.7 & 173 & 165 & 1.05 & 0.063 & 0.004 & 0.663 & 0.036 & 0.076 & 0.0012 & 720 & 122 & 516 & 22 & 471 & 7 \\
\hline 16 & 8.37 & 52.1 & 87.2 & 0.60 & 0.079 & 0.006 & 0.787 & 0.052 & 0.076 & 0.0018 & 1159 & 144 & 590 & 29 & 475 & 11 \\
\hline 17 & 10.9 & 61.7 & 114 & 0.54 & 0.069 & 0.006 & 0.700 & 0.053 & 0.076 & 0.0019 & 906 & 167 & 539 & 32 & 471 & 11 \\
\hline 18 & 14.6 & 89.4 & 149 & 0.60 & 0.066 & 0.004 & 0.671 & 0.039 & 0.076 & 0.0014 & 798 & 130 & 521 & 23 & 471 & 8 \\
\hline 19 & 10.0 & 77.3 & 95.7 & 0.81 & 0.064 & 0.005 & 0.645 & 0.044 & 0.076 & 0.0017 & 750 & 156 & 505 & 27 & 475 & 10 \\
\hline 20 & 10.3 & 81.6 & 108 & 0.75 & 0.059 & 0.004 & 0.554 & 0.034 & 0.071 & 0.0013 & 561 & 143 & 447 & 22 & 440 & 8 \\
\hline
\end{tabular}


表 2 昌宁-孟连结合带南汀河蛇绿岩堆晶辉长岩及辉长岩主量元素 $(w t \%)$ 及微量元素 $(p p m)$ 分析结果

\begin{tabular}{|c|c|c|c|c|c|c|}
\hline \multirow{2}{*}{ 样品编号 } & \multirow{2}{*}{$\begin{array}{c}\text { 辉长岩 } \\
11 \mathrm{NTH}-4\end{array}$} & \multicolumn{5}{|c|}{ 堆晶辉长岩 } \\
\hline & & 11 NTH-6 & 11NTH-7 & 11 NTH- 8 & 11 NTH-9 & $11 \mathrm{NTH}-10$ \\
\hline $\mathrm{SiO}_{2}$ & 46.46 & 49.40 & 52.11 & 51.71 & 50.13 & 50.19 \\
\hline $\mathrm{TiO}_{2}$ & 1.14 & 0.99 & 0.99 & 1.01 & 1.05 & 0.96 \\
\hline $\mathrm{Al}_{2} \mathrm{O}_{3}$ & 19.26 & 18.88 & 18.80 & 18.59 & 19.04 & 17.88 \\
\hline $\mathrm{Fe}_{2} \mathrm{O}_{3}^{\mathrm{T}}$ & 11.86 & 10.92 & 9.70 & 9.98 & 10.84 & 10.50 \\
\hline $\mathrm{MnO}$ & 0.19 & 0.17 & 0.19 & 0.20 & 0.17 & 0.16 \\
\hline $\mathrm{MgO}$ & 5.80 & 5.03 & 4.38 & 4.47 & 5.08 & 6.11 \\
\hline $\mathrm{CaO}$ & 10.26 & 8.84 & 7.99 & 8.51 & 8.68 & 9.41 \\
\hline $\mathrm{Na}_{2} \mathrm{O}$ & 3.24 & 3.68 & 3.87 & 3.73 & 3.54 & 3.25 \\
\hline $\mathrm{K}_{2} \mathrm{O}$ & 0.48 & 0.75 & 0.70 & 0.55 & 0.54 & 0.57 \\
\hline $\mathrm{P}_{2} \mathrm{O}_{5}$ & 0.23 & 0.20 & 0.20 & 0.21 & 0.18 & 0.14 \\
\hline LOI & 0.98 & 1.05 & 0.96 & 0.93 & 0.66 & 0.73 \\
\hline 总量 & 99.90 & 99.91 & 99.89 & 99.89 & 99.91 & 99.90 \\
\hline $\mathrm{Sc}$ & 40.5 & 22.9 & 23.6 & 24.8 & 26.0 & 30.7 \\
\hline $\mathrm{V}$ & 281 & 280 & 252 & 262 & 255 & 298 \\
\hline $\mathrm{Cr}$ & 129 & 59.8 & 47.6 & 45.5 & 61.7 & 113 \\
\hline Co & 41.4 & 32.0 & 25.4 & 26.2 & 30.9 & 31.2 \\
\hline $\mathrm{Ni}$ & 67.0 & 36.1 & 22.8 & 21.8 & 36.5 & 67.4 \\
\hline $\mathrm{Rb}$ & 3.80 & 6.53 & 7.08 & 3.95 & 3.63 & 3.39 \\
\hline $\mathrm{Sr}$ & 201 & 793 & 748 & 796 & 677 & 796 \\
\hline $\mathrm{Y}$ & 34.5 & 11.5 & 15.2 & 15.8 & 18.5 & 12.2 \\
\hline $\mathrm{Zr}$ & 137 & 22.3 & 16.4 & 19.4 & 35.7 & 20.5 \\
\hline $\mathrm{Nb}$ & 6.00 & 1.83 & 2.47 & 2.61 & 3.09 & 1.36 \\
\hline Cs & 0.23 & 0.39 & 0.29 & 0.18 & 0.18 & 0.33 \\
\hline $\mathrm{Ba}$ & 25.6 & 269 & 298 & 275 & 264 & 190 \\
\hline Hf & 3.36 & 0.77 & 0.64 & 0.73 & 1.05 & 0.73 \\
\hline $\mathrm{Ta}$ & 0.40 & 0.08 & 0.10 & 0.11 & 0.16 & 0.07 \\
\hline $\mathrm{Pb}$ & 2.05 & 4.30 & 5.24 & 6.67 & 5.03 & 4.45 \\
\hline $\mathrm{Th}$ & 0.48 & 0.14 & 0.25 & 0.25 & 0.26 & 0.28 \\
\hline $\mathrm{U}$ & 0.16 & 0.03 & 0.07 & 0.07 & 0.06 & 0.05 \\
\hline $\mathrm{La}$ & 6.17 & 11.9 & 14.2 & 14.7 & 14.1 & 10.7 \\
\hline $\mathrm{Ce}$ & 16.8 & 27.6 & 32.4 & 33.7 & 32.7 & 24.8 \\
\hline $\operatorname{Pr}$ & 2.80 & 3.92 & 4.37 & 4.62 & 4.62 & 3.54 \\
\hline $\mathrm{Nd}$ & 14.3 & 17.4 & 19.7 & 20.9 & 20.9 & 16.0 \\
\hline $\mathrm{Sm}$ & 4.36 & 3.66 & 4.08 & 4.25 & 4.50 & 3.48 \\
\hline $\mathrm{Eu}$ & 1.49 & 1.20 & 1.33 & 1.41 & 1.37 & 1.11 \\
\hline Gd & 5.29 & 3.18 & 3.64 & 3.83 & 4.18 & 3.03 \\
\hline $\mathrm{Tb}$ & 0.95 & 0.42 & 0.51 & 0.55 & 0.62 & 0.43 \\
\hline Dy & 6.24 & 2.31 & 2.96 & 3.01 & 3.63 & 2.40 \\
\hline Ho & 1.36 & 0.46 & 0.59 & 0.62 & 0.76 & 0.47 \\
\hline $\mathrm{Er}$ & 3.73 & 1.19 & 1.62 & 1.66 & 1.99 & 1.25 \\
\hline $\mathrm{Tm}$ & 0.55 & 0.17 & 0.23 & 0.24 & 0.27 & 0.18 \\
\hline $\mathrm{Yb}$ & 3.39 & 1.05 & 1.50 & 1.55 & 1.81 & 1.20 \\
\hline $\mathrm{Lu}$ & 0.53 & 0.16 & 0.24 & 0.24 & 0.27 & 0.18 \\
\hline
\end{tabular}




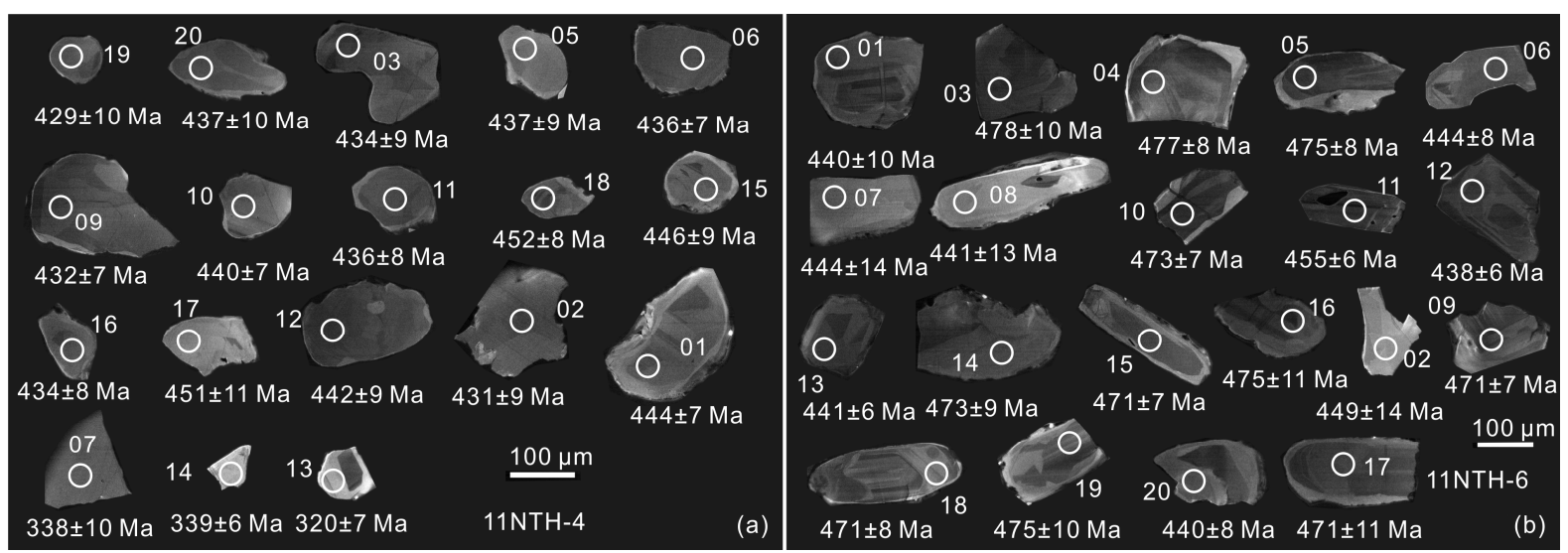

图 4 南汀河蛇绿岩辉长岩(a)、堆晶辉长岩(b)锆石 CL 图像
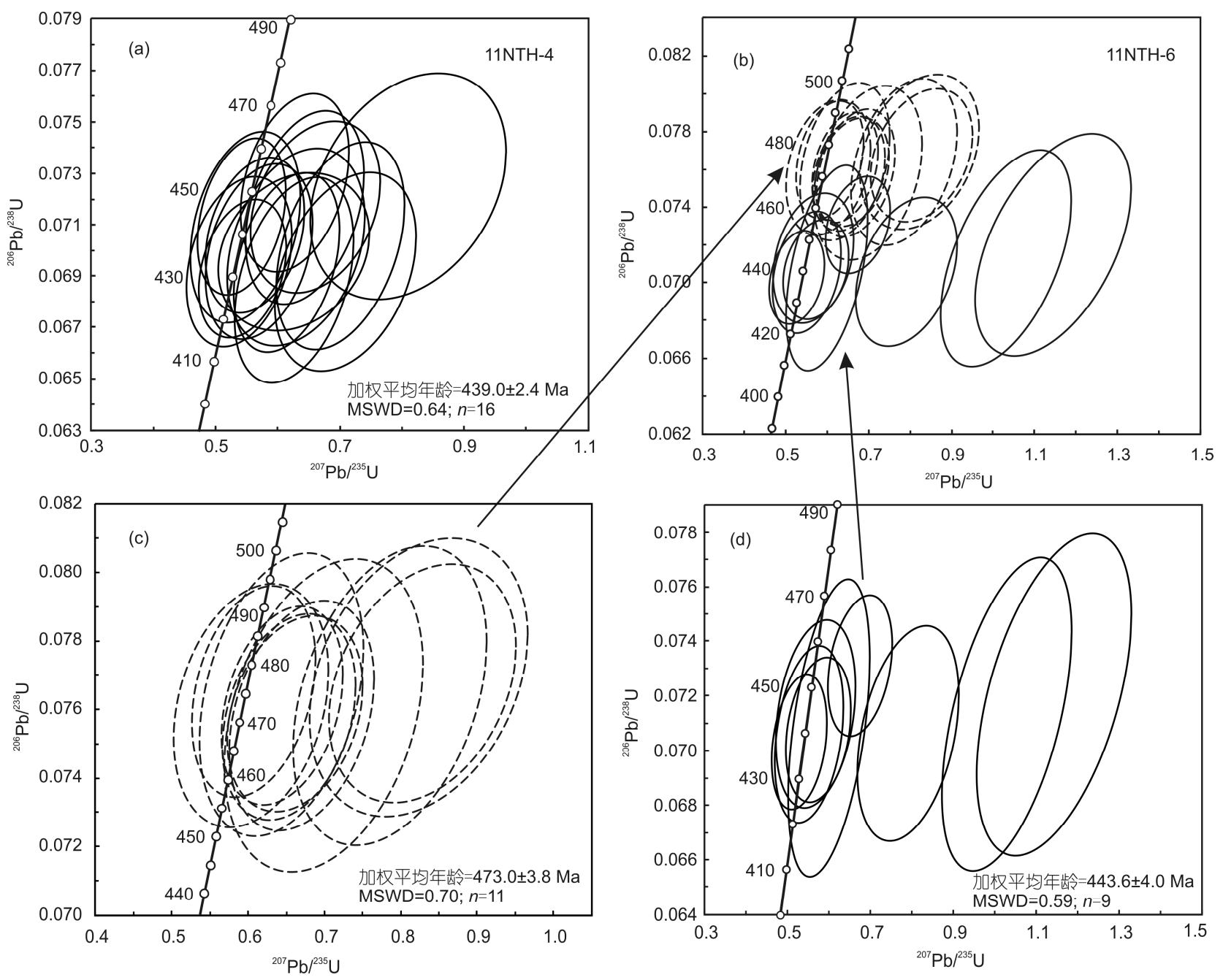

图 5 南汀河蛇绿岩辉长岩、堆晶辉长岩锆石 U-Pb 年龄谐和图

度高、显示结晶环带的锆石, $\mathrm{U}$ 和 $\mathrm{Th}$ 含量分别为 $35.0 \sim 237 \mathrm{ppm}, 12.1 \sim 262 \mathrm{ppm}, \mathrm{Th} / \mathrm{U}$ 均较高, 为 $0.35 \sim$ 1.11 (表 1), 也显示测定的锆石为岩浆成因, 9 个分析
点的 ${ }^{206} \mathrm{~Pb} /{ }^{238} \mathrm{U}$ 年龄为 $438 \sim 455 \mathrm{Ma}$ (表 1), 其 ${ }^{206} \mathrm{~Pb} /$ ${ }^{238} \mathrm{U}$ 加权平均年龄为 $443.6 \pm 4.0 \mathrm{Ma}(\mathrm{MSWD}=0.59, n=$ 9) (图 5(d)). 


\section{2 地球化学特征}

南汀河辉长岩及堆晶辉长岩地球化学表明(表 2), $\mathrm{SiO}_{2}$ 含量介于 $46.46 \%$ 52.11\%, 岩石样品具有中等 $\mathrm{MgO}$ (4.38\% 6.11\%), $\mathrm{TiO}_{2}(0.96 \% \sim 1.14 \%)$, 富 $\mathrm{Na}_{2} \mathrm{O}(3.24 \%$ $3.87 \%)$ 、贫 $\mathrm{K}_{2} \mathrm{O}\left(0.48 \%\right.$ 0.75\%)的特征. 随着 $\mathrm{SiO}_{2}$ 增 加, $\mathrm{TiO}_{2}, \mathrm{Fe}_{2} \mathrm{O}_{3}^{\mathrm{T}}, \mathrm{Al}_{2} \mathrm{O}_{3}, \mathrm{MgO}, \mathrm{CaO}$ 和 $\mathrm{P}_{2} \mathrm{O}_{5}$ 逐渐减少 (图未附), 表明这些岩石之间具有成因关系, 指示存 在岩浆的分离结晶作用. 考虑到岩石样品有轻微的 蚀变, 故此利用不活泼元素 $(\mathrm{Zr}, \mathrm{Ti}, \mathrm{Nb}, \mathrm{Y})$ 进行岩石 分类及构造环境的判别, 在 $\mathrm{Zr} / \mathrm{TiO}_{2}-\mathrm{Nb} / \mathrm{Y}$ 图解中所 有样品均落人玄武岩区(图 6(a)). 稀土元素总量略偏 高(67.92 91.63 ppm), 球粒陨石标准化曲线明显具有 两种分布形态, 第一种是轻稀土微弱亏损, 与 N-MORB 相似, 与果干加年山以及桃形湖地区的变 质堆晶辉长岩类似 ${ }^{[17,18]}$; 第二种是轻稀土富集, 曲线 右倾(图 6(b)), 与 E-MORB 相似. 微量元素蛛网图中
样品也有两种不同的分布型式, 第一种与 N-MORB 相似, 并且与桃形湖地区的堆晶辉长岩类似; 第二种 具有很低的高场强元素 $(\mathrm{Nb}, \mathrm{Ta}, \mathrm{Zr}, \mathrm{Hf}, \mathrm{Ti})$ 丰度, 有 的具有明显的负异常 (图 6(c)), 与岛弧玄武岩相似, 说明地幔源区可能受到俯冲带流体的影响 ${ }^{[19]}$, 这些 蛇绿岩很可能为 SSZ 型蛇绿岩.

\section{4 讨论}

\section{1 昌宁-孟连结合带南汀河地区早古生代洋壳 残余的识别}

本文对南汀河辉长岩以及堆晶辉长岩中锆石矿 物颗粒的标型内部结构研究表明, 两个样品的锆石 均具有补丁状、弱环带、宽窄不一的环带结构(图 4), $\mathrm{Th} / \mathrm{U}$ 比值在 0.35 1.11 之间, 与基性岩浆结晶的锆石 类似, 说明其不会是地壳物质混染形成, 而是在岩浆
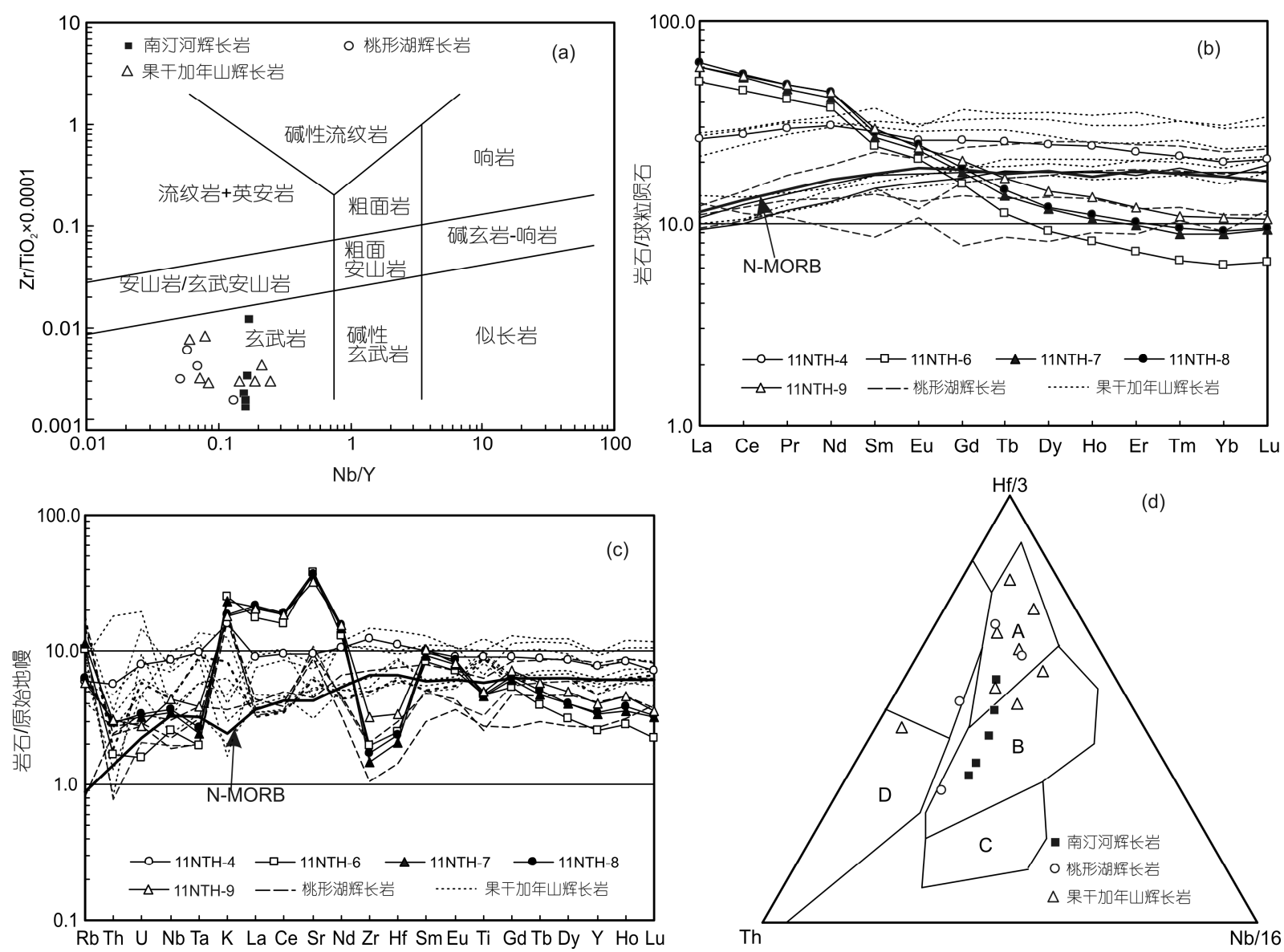

图 6 南汀河蛇绿岩辉长岩、堆晶辉长岩岩石分类(a)、REE 配分(b)、微量元素蛛网(c)及构造环境(d)图解 (d)中 A, N-MORB; B, E-MORB; C, 板内碱性玄武岩; D, 岛弧拉斑玄武岩 
系统中结晶形成. 辉长岩 16 个分析点 $\mathrm{U}-\mathrm{Pb}$ 年龄在 429 452 Ma, 加权平均年龄为 $439 \pm 2.4 \mathrm{Ma}$, 代表变 质基性岩浆结晶的时代. 堆晶辉长岩明显具有两组 $\mathrm{U}-\mathrm{Pb}$ 年龄, 一组 11 个测点范围为 471 478 $\mathrm{Ma}$, 加权 平均年龄为 $473.0 \pm 3.8 \mathrm{Ma}$, 可能代表了堆晶辉长岩早 期岩浆结晶的时代; 另外一组 9 个测点年龄范围在 438 455 Ma, 加权平均年龄为 $443.6 \pm 4.0 \mathrm{Ma}$, 可能代 表了堆晶辉长岩晚期岩浆的结晶时代, 并且年轻的这 组年龄与辉长岩的结晶时代在误差范围内完全一致. 更重要的是, 岩石组合和地球化学分析数据结果表明, 不论是辉长岩还是堆晶辉长岩, 均具有类似于 $\mathrm{N}$ MORB 或 E-MORB 的微量元素地球化学组成(图 6(d)). 结合部分岩石具有很低的高场强元素含量(图 6(c)), 说明这些基性岩浆很可能形成于弧后裂谷盆地构造环 境 ${ }^{[19]}$. 这些年代学和地球化学特征表明, 昌宁-孟连结 合带南汀河地区 444 439 Ma 时期应该发育洋盆.

\section{2 昌宁-孟连结合带与龙木错-双湖结合带的关系}

区域上昌宁-孟连蛇绿混杂岩被晚三叠世三岔河 组 $\left(\mathrm{T}_{3} s c\right)$ 、中侏罗世花开左组 $\left(\mathrm{J}_{2} h\right)$ 角度不整合覆盖, 而该带早石炭世平掌组 $\left(\mathrm{C}_{1} p z\right)$ 火山岩广泛出露, 被认 为是昌宁-孟连洋盆发育鼎盛时期的产物, 上覆渔塘 寨组 $(\mathrm{CP} y)$ 碳酸盐岩沉积则代表洋盆开始萎缩、水体 逐渐变浅的过程; 由此认为昌宁-孟连结合带的打开 时间不晚于早石炭世 ${ }^{[10]}$. 后来众多的研究者在昌宁孟连地区发现了早泥盆世-二叠纪放射虫硅质岩, 以 泥盆纪早期的 Monograptus uniformis 带为代表; 梅 里雪山西坡一套深水复理石沉积的硅质岩中发育早 石炭世 Palaeory phosty.lus uar spina 放射虫分子; 扎 玉-碧土一带硅质岩中发现晚石炭世-二叠纪 Albaillea sp. Pseudea Ibailla sp. ${ }^{[20]}$; 另外硅质岩的沉积地球化 学、稀土和稳定同位素以及放射虫古生态学多学科综 合研究 ${ }^{[2,21,22]}$ 也显示了深海洋盆的沉积环境; 在孟连 曼信、耿马弄巴等地也可见泥盆纪、石炭纪和早二叠 世的放射虫硅质岩. 研究区北侧铜厂街蛇绿岩中辉 长岩中角闪石 $\mathrm{K}-\mathrm{Ar}$ 等时线年龄为 $385 \mathrm{Ma}^{[23,24]}, 1: 25$ 万临沧县幅在双江县东约 $12 \mathrm{~km}$ 的蒙化寨一带获得 纹层状斜长角闪岩的铅同位素模式年龄为 $381 \mathrm{Ma}^{[10]}$, 为中泥盆世的地质记录; 因此多数学者认为昌宁-孟 连洋盆的扩张时代是泥盆纪. 还有研究者根据滇西 藏东三江地区主要地块碰撞拼合的古地磁资料, 并 结合与构造活动有关的沉积记录及古生物地理信息
的对比研究, 认为昌宁-孟连结合带可能于晚奥陶世 Katian 期中期(约 $450 \mathrm{Ma}$ )扩张 ${ }^{[25,26]}$. 以上所有证据 均显示昌宁-孟连结合带存在晚古生代的洋盆信息. 结合本文在南汀河地区发现的 444 439 Ma 洋壳残 余记录, 表明昌宁-孟连结合带至少存在早古生代和 晚古生代两期蛇绿岩.

近年来，在青藏高原芫塘中部的龙木错-双湖结 合带, 也获得了较多存在早古生代洋盆扩张的证据. 藏北㒸塘中部果干加年山地区的蛇绿混杂岩及超高 压变质岩分布于龙木错-双湖结合带中 ${ }^{[27]}$, 蛇绿岩中 堆晶辉长岩 SHRIMP 锆石 U-Pb 年龄为 $438 \pm 11 \mathrm{Ma}^{[28]}$, $432 \pm 7 \mathrm{Ma}$ 和 $461 \pm 7 \mathrm{Ma}^{[29]}$, 可能形成于洋中脊的构造 环境 ${ }^{[18]}$. 另外, 在藏北芫塘桃形湖地区还发现了一 套变质超基性岩、变质堆晶辉长岩、变质辉长岩(辉 绿岩)、变质玄武岩和斜长花岗岩岩石组合, 显示出 较为完整的蛇绿岩套层序特征, 并获得变质堆晶辉 长岩 SHRIMP 锆石 U-Pb 年龄为 $467 \pm 4 \mathrm{Ma}$, 其锆石 $\varepsilon_{\mathrm{Hf}}(t)$ 加权平均值为 $5.0 \pm 0.3$, 反映其岩浆源区为亏损 型地幔, 基性岩具有与洋中脊玄武岩类似的地球化 学组成 ${ }^{[17]}$. 这些资料表明, 龙木错-双湖结合带存在 早古生代蛇绿岩. 另外, 已有研究者在芫塘中部角木 日地区识别出二叠纪准洋中脊型蛇绿岩、三叠纪含放 射虫硅质岩, 同时在双湖以东才多茶卡地区识别出

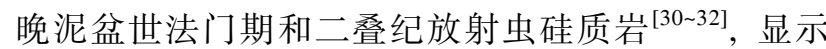
芫塘地区存在晚古生代蛇绿岩. 以上资料表明芫塘 地区的龙木错-双湖结合带至少也存在早古生代和晚 古生代蛇绿岩残片. 另外由于蛇绿岩的构造侵位与 洋中脊或弧后盆地转化为俯冲带有关, 因此这些基 性-超基性岩石形成的构造环境可能兼具洋中脊或弧 后裂谷性质.

一般来说，如果共生的基性岩只表现为 N-MORB 型微量元素分布, 则可能形成于洋中脊环 境; 如果共生的基性岩既表现为 MORB 型微量元素 分布，也表现出低的高场强元素含量，则可能形成于 弧后裂谷盆地 ${ }^{[19]}$. 由此可见, 本文获得的昌宁-孟连 结合带蛇绿岩年龄与芫塘果干加年山以及桃形湖一 带早古生代蛇绿岩的形成时代接近，构造环境也非 常相似，可能形成于一种大规模的弧后裂谷盆地环 境，由于古生代弧后盆地关闭和弧-陆碰撞而得以侵 位 ${ }^{[19]}$. 如果从形成时代和构造环境角度来考虑，可 将藏北差塘地区的果干加年山以及桃形湖蛇绿岩与 三江地区昌宁-孟连结合带的南汀河蛇绿岩联系起来, 
二者可能代表了一个统一的古特提斯洋壳的残余, 即龙木错-双湖-昌宁-孟连古特提斯洋, 并且其至少 从奥陶纪一直延续到二叠纪. 结合东侧临沧-敌海晚 古生代火山-岩浆弧的时代, 认为昌宁-孟连洋盆早古 生代末期向东俯冲消减形成以 421 418 Ma 的大中 河火山岩, 闭合于二叠纪末、早三叠世发生弧-陆碰 撞作用 ${ }^{[33 ~ 36]}$, 最终被上三叠统普遍不整合覆盖.

\section{5 结论}

(1) 昌宁-孟连结合带南汀河蛇绿岩中堆晶辉长
岩及辉长岩 LA-ICPMS 锆石 U-Pb 年龄为 444 439 Ma, 并具有 N-MORB 型的地球化学性质, 指示昌宁-孟连 带存在早古生代蛇绿岩, 表明昌宁-孟连结合带存在 444 439 Ma 的洋盆信息, 可能是弧后裂谷盆地.

(2) 南汀河堆晶辉长岩的年龄与羌塘中部龙木 错-双湖结合带的果干加年山、桃形湖的堆晶辉长岩 年龄接近, 地球化学性质相似, 证明昌宁-孟连结合 带与龙木错-双湖结合带相连, 它们可能代表了一个 统一的古特提斯洋壳的残余, 由于古生代弧后盆地 关闭和弧-陆碰撞而得以侵位. 助, 在此一并致谢!

\section{参考文献}

1 刘本培. 古大陆边缘沉积地质. 武汉: 中国地质大学出版社, 1992. 1-211

2 刘本培, 冯庆来, 方念乔, 等. 滇西南昌宁-孟连带和澜沧江带古特提斯多岛洋构造演化. 地球科学, 1993, 18: 529-539

3 钟大春, 吴根耀. 滇东南发现蛇绿岩. 科学通报, 1998, 43: 1365-1370

4 崔春龙, 曾允孚, 段丽兰, 等. 滇西昌宁-孟连带存在一个古生代大洋吗? 沉积学报, 1999, 17: 176-182

5 莫宣学, 沈上越, 朱勤文. 三江中南段火山岩-蛇绿岩与成矿. 北京：地质出版社, 1998. 1-128

6 Metcalfe I. Gondwanaland origin, dispersion, and accretion of East and Southeast Asian continental terranes. J South Am Earth Sci, 1994, 7: $333-347$

7 沈上越, 冯庆来, 刘本培, 等. 昌宁-孟连带洋脊、洋岛型火山岩研究. 地质科技情报, 2002, 21: 13-17

8 张旗, 周德进, 赵大升, 等. 滇西古特提斯造山带的威尔逊旋回: 岩浆活动记录和深部过程讨论. 岩石学报, 1996, 12: 17-28

9 杨文强, 冯庆来, 段向东. 滇西南昌宁-孟连构造带晚泥盆世枕状玄武岩和层状硅质岩的特征. 地质通报, 2007, 26: 739-747

10 云南省地质调查院. 中华人民共和国 1: 25 万凤庆县幅区域地质调查报告. 2008

11 Liu Y, Hu Z, Gao S, et al. In situ analysis of major and trace elements of anhydrous minerals by LA-ICP-MS without applying an internal standard. Chem Geol, 2008, 257: 34-43

12 Liu Y, Gao S, Hu Z, et al. Continental and oceanic crust recycling-induced melt-peridotite interactions in the Trans-North China Orogen: $\mathrm{U}-\mathrm{Pb}$ dating, $\mathrm{Hf}$ isotopes and trace elements in zircons from mantle xenoliths. J Petrol, 2010, 51: 537-571

13 Ludwig K R. User's manual for Isoplot 3.00: A geochronological toolkit for Microsoft Excel. Berkeley Geochronology Center Spec Pub, 2003, 41-70

14 Chen J, Xu J, Wang B, et al. Origin of Cenozoic alkaline potassic volcanic rocks at KonglongXiang, Lhasa terrane, Tibetan Plateau: Products of partial melting of a mafic lower-crustal source? Chem Geol, 2010, 273: 286-299

15 吴元保, 郑永飞. 锆石成因矿物学研究及其对 U-Pb 年龄解释的制约. 科学通报, 2004, 49: 1589-1604

16 Hoskin P W O, Black L P. Metamorphic zircon formation by solid-state recrystallization of protolith igneous zircon. J Metamor Geol, 2000, 18: 423-439

17 翟庆国, 王军, 李才, 等. 青藏高原㒸塘中部中奥陶世变质堆晶辉长岩锆石 SHRIMP 年代学及 Hf 同位素特征. 中国科学 D 辑: 地 球科学, 2010, 40: 565-573

18 翟庆国, 李才, 黄小鹏. 西藏㒸塘中部古特提斯洋残片? 一一来自果干加年山变质基性岩地球化学证据. 中国科学 D 辑: 地球科学, 2007, 37: 866-872

19 Zheng Y F. Metamorphic chemical geodynamics in continental subduction zones. Chem Geol, 2012, doi: 10.1016/j.chemgeol.2012.02.005

20 李文昌, 潘桂棠, 侯增谦, 等. 西南“三汇”多岛弧盆-碰撞造山成矿理论与勘查技术. 北京：地质出版社, 2010. 1-107

21 丁林, 钟大㐘. 滇西昌宁-孟连带古特提斯洋硅质岩稀土元素和铈异常特征. 中国科学 B 辑, 1995, 25: 93-100

22 冯庆来, 崔新省, 刘本培. 滇西澜沧老厂晚二叠世双壳动物群的发现. 地球科学, 1992, 17: 512-520

23 张旗, 李达周. 义敦型镁铁-超锠铁岩的主要特征及其与蛇绿岩的对比. 岩石学报, 1990, 3: 33-42 
24 从柏林, 吴根耀, 张旗, 等. 中国滇西古特提斯构造带岩石大地构造演化. 中国科学 B 辑, 1993, 23: 1201-1207

25 李朋武, 高锐, 崔军文, 等. 西藏和云南三江地区特提斯洋盆演化历史的古地磁分析. 地球学报, 2005, 26: 387-404

26 李朋武, 高锐, 崔军文, 等. 滇西藏东三江地区主要地块碰撞拼合的古地磁分析. 沉积与特提斯地质, 2003, 23: 28-34

27 李才, 翟庆国, 董永胜, 等. 青藏高原芫塘中部榴辉岩的发现及其意义. 科学通报, 2006, 51: 70-74

28 李才, 董永胜, 翟庆国, 等. 青藏高原羌塘早古生代蛇绿岩一一堆晶辉长岩的锆石 SHRIMP 定年及其意义. 岩石学报, 2008, 24: $31-36$

29 王立全, 潘桂棠, 李才, 等. 藏北㒸塘中部果干加年山早古生代堆晶辉长岩的锆石 SHRIMP U-Pb 年龄一一兼论原-古特提斯洋的演 化. 地质通报, 2008, 27: 2045-2056

30 朱同兴, 张启跃, 董瀚, 等. 藏北双湖才多茶卡地区构造混杂岩中新发现晚泥盆世和晚二叠世放射虫硅质岩. 地质通报, 2006, 25: $1413-1418$

31 翟庆国, 李才, 程立人, 等. 西藏羌塘角木日地区二叠纪蛇绿岩的地质特征及意义. 地质通报, 2004, 23: 1228-1230

32 翟庆国, 李才, 黄小鹏. 西藏㒸塘中部角木日地区二叠纪玄武岩的地球化学特征及其构造意义. 地质通报, 2006, 25: 1419-1427

33 毛晓长, 王立全, 李冰, 等. 云县-景谷火山弧带大中河晚志留世火山岩的发现及其地质意义. 岩石学报, 2012, 28: 1517-1528

34 Zhu D C, Zhao Z D, Niu Y L, et al. The origin and pre-Cenozoic evolution of the Tibetan Plateau. Gondwana Res, 2012, doi: 10.1016/j.gr.2012.02.002

35 潘桂棠, 王立全, 丁俊, 等. 青藏高原及邻区地质图(1:1500000)(新版). 北京：地质出版社, 2012. 1-319

36 潘桂棠, 王立全, 朱弟成. 青藏高原区域地质调查中几个重大科学问题的思考. 地质通报, 2004, 23: 12-19 